\title{
The ongoing quest for an ideal surgical repair for tetralogy of Fallot: Focus on the pulmonary valve
}

\author{
Charles D. Fraser, Jr, MD
}

See related article on pages 1358-63.

Isn't it fascinating to observe that there are so many different ways congenital heart surgeons perform tetralogy of Fallot (TOF) repairs? Even in an era when information flows freely, and we are virtually deluged by meetings, journals, and on-line media, surgeons continue to debate the proper treatment strategy for this common congenital cardiac problem. After decades of surgical progress, and with many surgeons and surgical units consistently achieving hospital survivals greater than $99 \%$, should we not, finally, be able to agree on the best surgical methodology? To my view, the answer is probably not yet, but perhaps we can all at least agree that we still have a core question to address. What I am alluding to, of course, is the optimal surgical strategy to achieve both excellent early results and durable long-term right ventricular function. Given the accruing data concerning the long-term challenges patients face years or decades after corrective operations for TOF, overwhelmingly related to right heart performance, it is entirely justifiable to continue to refine surgical strategies. Thus preservation of tricuspid valve function, maintenance of a normal conduction system, limiting injury to the right ventricular infundibulum, and promoting native pulmonary valve function and growth all should arguably have some relevance to long-term right heart performance and patient well-being. ${ }^{1-5}$

In this issue of the Journal, Vida and colleagues ${ }^{6}$ have added important insight into ways that surgeons can attempt to affect long-term right heart performance through aggressive attempts to preserve native pulmonary valve function in patients undergoing TOF repair. There are several key points in this article. Through meticulous attention to technical detail and native valve morphology, Vida and colleagues have been able to "preserve" native pulmonary valve function in $56 \%$ of their patients

From the Department of Congenital Heart Surgery, Texas Children's Hospital, Baylor College of Medicine, Houston, Tex.

Disclosures: Author has nothing to disclose with regard to commercial support.

Received for publication Feb 23, 2015; accepted for publication Feb 25, 2015.

Address for reprints: Charles D. Fraser, Jr, MD, Department of Congenital Heart

Surgery, Texas Children's Hospital, Baylor College of Medicine, 6621 Fannin

St, West Tower, TCH 19th Floor, Houston, TX 77030 (E-mail: charlesf@bcm.

edu or cdfraser@texaschildrens.org).

J Thorac Cardiovasc Surg 2015;149:1364

$0022-5223 / \$ 36.00$

Copyright (C) 2015 by The American Association for Thoracic Surgery

http://dx.doi.org/10.1016/j.jtcvs.2015.02.052

undergoing TOF repair. Useful adjuncts include on-table balloon pulmonary valve dilation, "delamination" of deficient pulmonary valve cusps, and commissural resuspension. Early results appear encouraging, at least in terms of echocardiographic evidence of pulmonary valve insufficiency; however, $95 \%$ of patients have been left

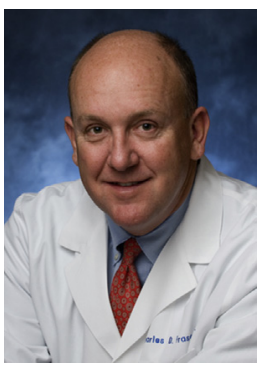
with at least moderate right ventricular hypertension (pulmonary valve pressure gradients of at least $20-40 \mathrm{~mm} \mathrm{Hg}$ ). Unfortunately, this study cannot tell us whether these efforts will translate into long-term benefit. Will these surgically repaired pulmonary valves continue to grow and maintain adequate function and competence? Is it better to preserve some degree of pulmonary valve competence at the expense of ongoing moderate right ventricular hypertension?

These questions will only be answered through diligent, objective collection of long-term follow-up data. As with other chronic diseases in the evolving field of transition medicine, patients undergoing repair with the described surgical modifications need careful, objective follow-up and study. Only then will we truly know what effects this strategy and others have on right ventricular function and outcomes in patients after TOF repair.

\section{References}

1. McKenzie ED, Maskatia SA, Mery C. Surgical management of tetralogy of Fallot: in defense of the infundibulum. Semin Thorac Cardiovasc Surg. 2013;25:206-12.

2. Morales DL, Zafar F, Heinle JS, Ocampo EC, Kim JJ, Relyea K, et al. Right ventricular infundibulum sparing (RVIS) tetralogy of Fallot repair: a review of over 300 patients. Ann Surg. 2009;250:611-7.

3. Stewart RD, Backer CL, Young L, Mavroudis C. Tetralogy of Fallot: results of pulmonary valve-sparing strategy. Ann Thorac Surg. 2005;80:1431-8.

4. van der Hulst AE, Hylkema MG, Vliegen HW, Delgado V, Hazekamp MG, Rijlaarsdam ME, et al. Mild residual pulmonary stenosis in tetralogy of Fallot reduces risk of pulmonary valve replacement. Ann Thorac Surg. 2012;94:2077-82.

5. O'Meagher S, Ganigara M, Munoz P, Tanous DJ, Chard RB, Celermajer DS, et al. Right ventricular outflow tract enlargement prior to pulmonary valve replacement is associated with poorer structural and functional outcomes, in adults with repaired tetralogy of Fallot. Heart Lung Circ. 2014;23:482-8.

6. Vida VL, Angelini A, Guariento A, Frescura C, Fedrigo M, Padalino M, et al. Preserving the pulmonary valve during early repair of tetralogy of Fallot: anatomic substrates and surgical strategies. J Thorac Cardiovasc Surg. 2015;149:1358-63. 